Preprint

UCRL-JC-144751

\title{
On the Development of Microstructure in A Metal Matrix Composite Using Nano-Materials
}

\author{
V. A. Popov, D. R. Lesuer, I. A. Kotov, V. V. Ivanov, A. A. \\ Aksenov, I. I. Khodos, G. L. Klimenko, O. M. Smirnov, A. \\ M. Murzakaev, S. V. Zayats
}

This article was submitted to 2002 The Minerals, Metals and Materials Society Annual Meeting, $2^{\text {nd }}$ International Symposium on Ultrafine Grained Materials, Seattle, WA., February 17-21, 2002

Lawrence

Livermore

National

Laboratory

September 10, 2001 


\section{DISCLAIMER}

This document was prepared as an account of work sponsored by an agency of the United States Government. Neither the United States Government nor the University of California nor any of their employees, makes any warranty, express or implied, or assumes any legal liability or responsibility for the accuracy, completeness, or usefulness of any information, apparatus, product, or process disclosed, or represents that its use would not infringe privately owned rights. Reference herein to any specific commercial product, process, or service by trade name, trademark, manufacturer, or otherwise, does not necessarily constitute or imply its endorsement, recommendation, or favoring by the United States Government or the University of California. The views and opinions of authors expressed herein do not necessarily state or reflect those of the United States Government or the University of California, and shall not be used for advertising or product endorsement purposes.

This is a preprint of a paper intended for publication in a journal or proceedings. Since changes may be made before publication, this preprint is made available with the understanding that it will not be cited or reproduced without the permission of the author.

This work was performed under the auspices of the United States Department of Energy by the University of California, Lawrence Livermore National Laboratory under contract No. W-7405-Eng-48.

This report has been reproduced directly from the best available copy.

Available electronically at http://www.doc.gov/bridge

Available for a processing fee to U.S. Department of Energy

And its contractors in paper from

U.S. Department of Energy

Office of Scientific and Technical Information

P.O. Box 62

Oak Ridge, TN 37831-0062

Telephone: (865) 576-8401

Facsimile: (865) 576-5728

E-mail: reports@adonis.osti.gov

Available for the sale to the public from

U.S. Department of Commerce

National Technical Information Service

5285 Port Royal Road

Springfield, VA 22161

Telephone: (800) 553-6847

Facsimile: (703) 605-6900

E-mail: orders@ntis.fedworld.gov

Online ordering: http://www.ntis.gov/ordering.htm

\section{OR}

Lawrence Livermore National Laboratory

Technical Information Department's Digital Library

http://www.llnl.gov/tid/Library.html 


\title{
ON THE DEVELOPMENT OF MICROSTRUCTURE IN A METAL MATRIX COMPOSITE USING NANO-MATERIALS
}

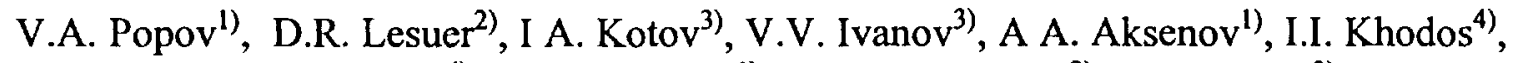 \\ G.L. Klimenko ${ }^{4)}$, O.M. Smirnov ${ }^{\text {() }}$, A.M. Murzakaev ${ }^{3)}$, S.V. Zayats ${ }^{3)}$ \\ 1) Moscow State Institute of Steel and Alloys, Moscow, Russia \\ ${ }^{2)}$ Lawrence Livermore National Laboratory, L-342, Livermore, CA, USA 94551 \\ ${ }^{3)}$ Institute of Electrophysics of Ural Branch Academy of Science, Ekaterinburg Russia \\ ${ }^{4)}$ Institute of Microelectronics Technology and High Purity Materials, Chernogolovka, Russia
}

\begin{abstract}
Metal matrix composites (MMCs) containing matrices with nanometer grain sizes have been produced from pure aluminum nano-powders (particle sizes $50-200 \mathrm{~nm}$ ) with $\mathrm{SiC}$ reinforcement (particle sizes $3-10 \mu \mathrm{m}$ ). The pure $\mathrm{Al}$ nano-powders were produced using an exploding wire technique. Dynamic loading using a magnetic impulse technique has been used to compact the MMC to high density. The dynamic compaction process results in excellent wetting of the $\mathrm{SiC}$ particles by the nanocrystalline $\mathrm{Al}$ powders, and the retention of a nanocrystalline grain size in the MMC. Microstructural analysis of the resulting MMC showed a highly uniform distribution of $\mathrm{SiC}$ particles with no visible defects or pores and the absence of deleterious phases (such as $\mathrm{Al}_{4} \mathrm{C}_{3}$ ) at the interfaces between the aluminum nano-grains and the $\mathrm{SiC}$ particles. The microstructures produced and the evolution of microstructure during dynamic compaction has also been studied using TEM and found to progress in three stages. These three stages are described.
\end{abstract}




\section{Introduction}

Metal Matrix Composites (MMCs) provide the opportunity to design advanced materials for a wide range of engineering applications. In many cases, $\mathrm{MMCs}$ can have properties and characteristics that are not attainable in either metals or alloys. As a result, MMCs have recently been examined and utilized for a wide range of industrial applications [1]. It is generally recognized that the properties of MMCs improve with decreasing reinforcement size and decreasing grain size in the matrix alloy [2]. However, current methods for producing MMCs (for example aluminum alloys reinforced with $\mathrm{SiC}$ ), which often involve casting techniques, have serious limitations with the minimum size of reinforcement that can be successfully processed as well as the minimum grain size of the resulting product. In addition, current casting techniques have processing difficulties that limit the combinations of matrix alloy and reinforcement that can be successfully combined into an MMC. Perhaps the most serious limitation is poor wetting (or even lack of wetting) between the matrix and reinforcement. There are techniques for improving wetting through modifications of the reinforcement or through minor additions to the molten alloy. However, these methods are generally either labor intensive or result in a MMC with inferior properties.

Dynamic compaction of the MMC components under very high pressure offers the possibility for improved wetting of matrix and reinforcement. In addition, with dynamic compaction it is possible to process matrix alloys with nano-scale grain size without significant grain growth. The present study was focused on the investigation and development of new MMC production methods using a magnetic impulse technique. Surface active nano-powders were used for the matrix, which resulted in improved wetting and service properties. It is also possible to use nano-scale powders for the reinforcing phase as well. Present methods of casting aluminum $\mathrm{MMCs}$ do not use SiC particle less than $9-10 \mu \mathrm{m}$ in size. Using the magnetic impulse technique for dynamic compaction, $\mathrm{SiC}$ particles less than $1 \mu \mathrm{m}$ can be successfully processed. These MMCs with smaller reinforcement size will have better properties. These new materials are expected to have a wide range of products in aircraft, space and automotive applications. In this paper we report on the microstructures produced due to dynamic compaction of nano-powders using the magnetic impulse technique. The evolution of the microstructure during dynamic compaction is also described.

\section{Processing and Characterization Procedures}

For the present study, MMCs were produced from commercially pure aluminum nanopowder with particle size of 50-200 nm and silicon carbide powder with particle size $3-10$ $\mu \mathrm{m}$. The mass fraction of silicon carbide powder in these composites was varied from $20-$ $40 \%$. The aluminum nano-powder was produced using the exploding wire technique [3-5] and stored in a hexane solution. The component powders were stirred in a conserving liquid (hexane) with simultaneous ultrasonic vibration so as to obtain a uniform distribution of reinforcement within the matrix component. After mixing, the powders were settled out of the hexane and then placed in a vacuum press-box for drying. The dried mixture was then heated to $300^{\circ} \mathrm{C}$ and compacted by dynamic loading using the uniaxial magnetic-impulse (MI) pressing technique [6-8]. This method generated a load of up to $900 \mathrm{kN}$ and a pulse duration of $500 \mu \mathrm{s}$. The pressure applied to the samples was about 1-2 GPa. The resulting samples 
had a diameter of $15 \mathrm{~mm}$ and a length of $10-15 \mathrm{~mm}$. Prior to magnetic impulse pressing, the powder was degassed in a vacuum with residual pressure of $1 \mathrm{~Pa}$ and simultaneous heating the powder to $200-400^{\circ} \mathrm{C}$. This process removed gases from the surface of the particles and prevented oxidation of the metallic component of the powder mixture. Pressing was made during continuous vacuum pumping at temperatures from 20 to $300^{\circ} \mathrm{C}$. The resulting microstructure was then studied with a "Neophot-30" optical microscope and a JSM-35CF scanning electron microscope. The fine structure of the MMC was investigated with a transmission electron microscope "JEM 2000 FX". Specimens for transmission microscopy were prepared using an ion beam thinning method.

\section{Microstructure and Microstructural Evolution}

Analysis of cross-sectional surfaces of the MMC produced in this study after compaction showed a homogeneous distribution of $\mathrm{SiC}$ particles within the monolithic matrix. The MMC had an average grain size in the matrix of 100-200 nm. In addition, there were no visible defects and pores. These microstructural features are expected to result in a high density as a result of dynamic compaction.

Examination of samples by transmission electron microscopy revealed three stages of structure evolution in the MMC matrix due to dynamic compaction. Before compaction matrix nanoparticles have a spherical shape. During the first stage of compaction (Fig. 1), the spherical particles of various sizes form a continuous and porous compact due to welding of particles at contact points. The particles retain their spherical shape.

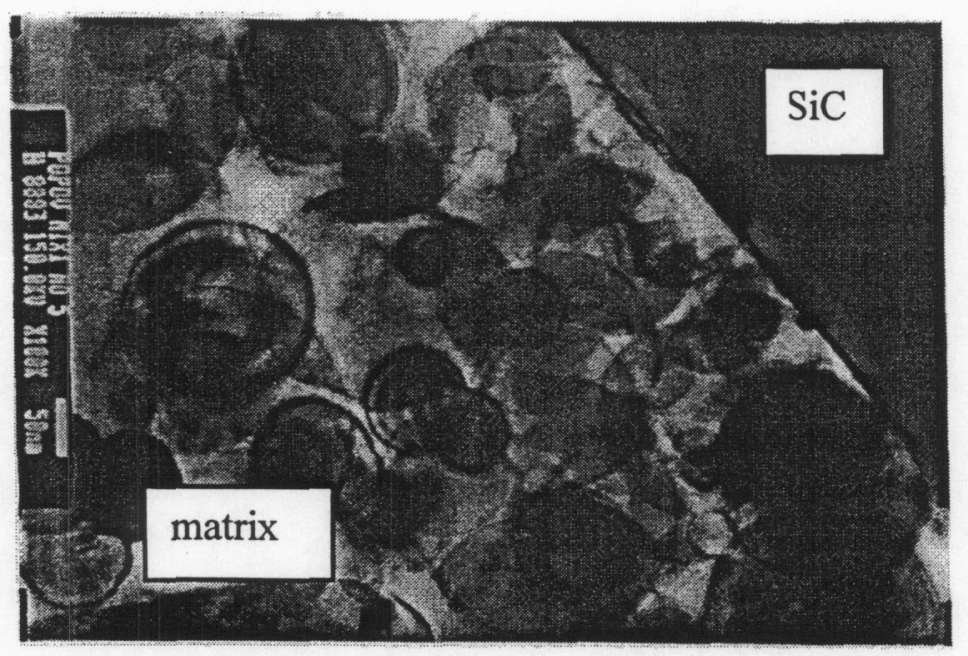

Figure 1. TEM showing the formation of the matrix structure. Spherical particles of various sizes form a dense compact due to welding at contact points.

During the second stage of microstructural evolution, nano-particles become nano-grains in the Al matrix (Fig. 2). This structure results as particles deform, rotate and snag against each other. The deformation produces a microstructure that has maximum dense packing of particles. However, as shown in Fig. 2(a) and (b), individual particles do not lose their identity and the result is an aluminum matrix of nano-grains. 


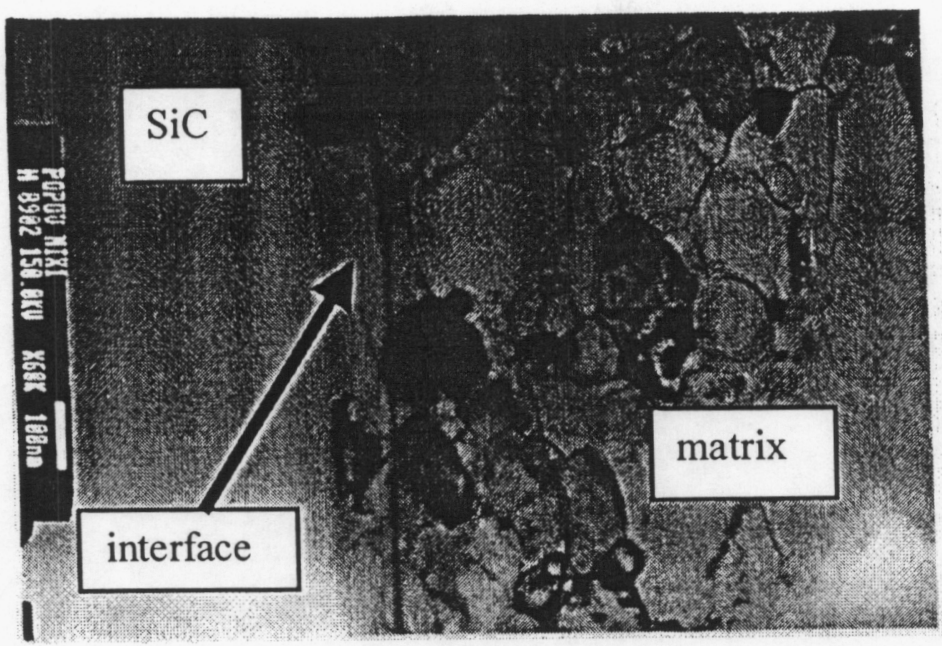

(a)

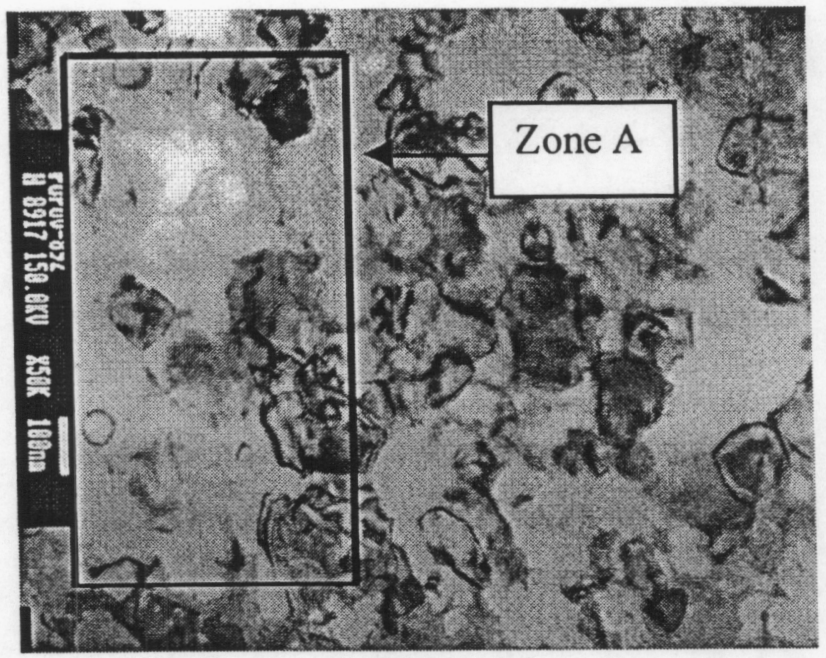

(b)

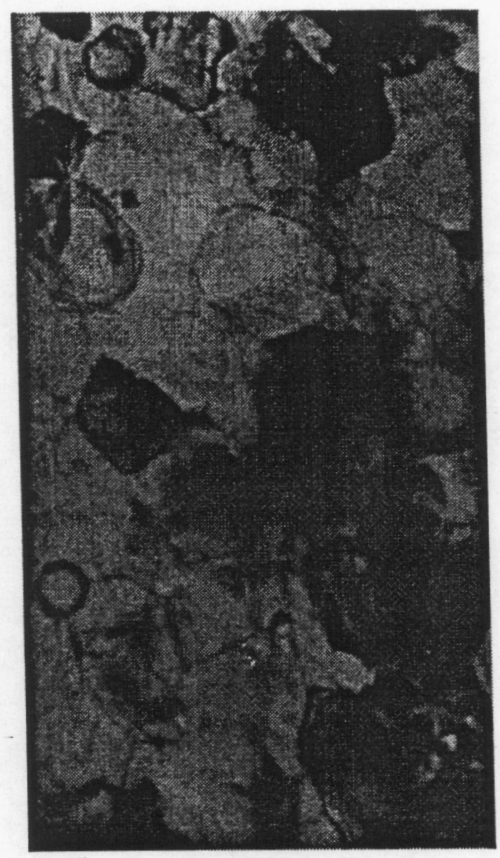

(c)

Figure 2. Second stage in the formation of matrix microstructure - nano-particles become nano-grains in the aluminum matrix. (a) Interface between the aluminum matrix and silicon carbide reinforcement, (b) microstructure in the aluminum matrix and (c) additional detail in Zone A from (b). (TEM).

Figure 3 shows the matrix microstructure after the third stage of microstructural evolution. During this third stage, some nano-grains loose their identity. These grains become consolidated by a mechanism of collective recrystallization in which the boundaries between individual contacting particles disappear. Such a structure is typical for MMCs formed from a matrix of nano-scale powders using dynamic compaction. Subsequent thermal treatment can change this structure. 


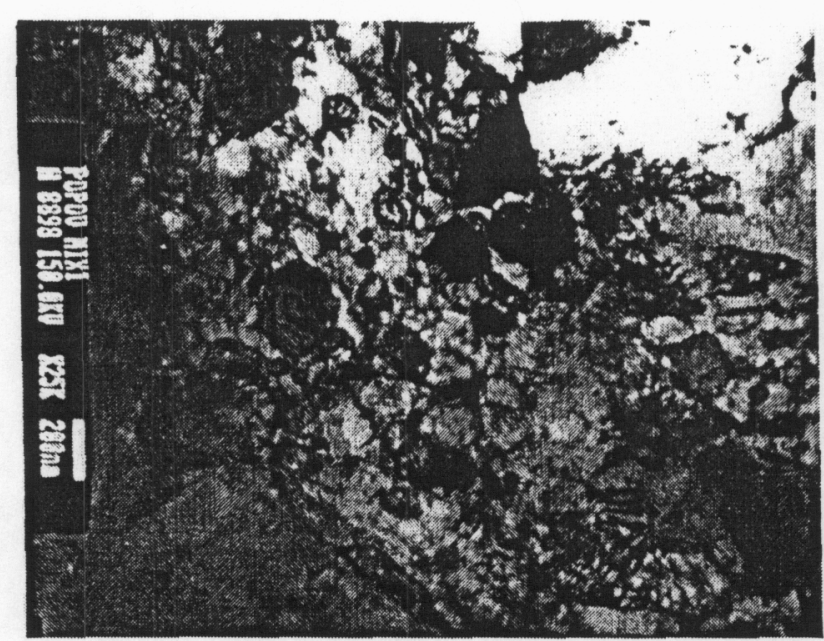

(a)

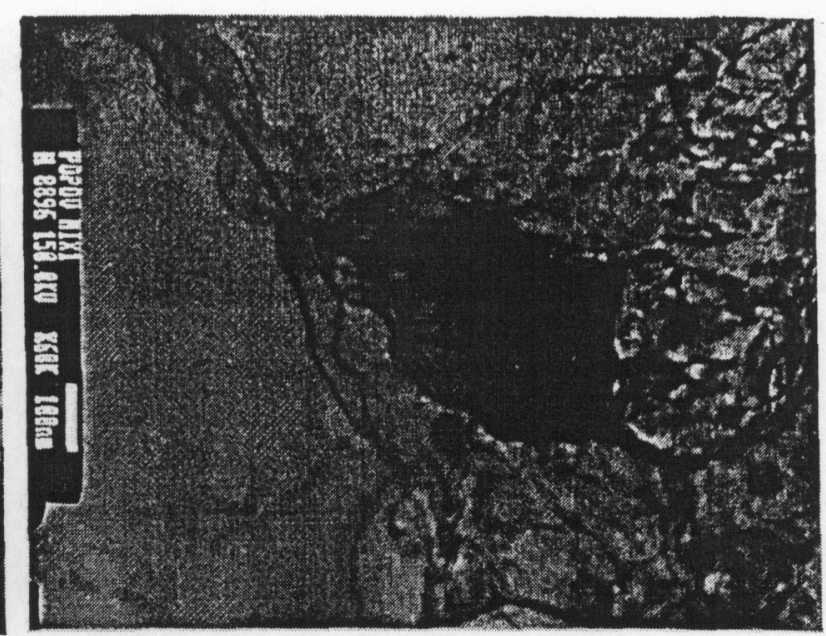

(b)

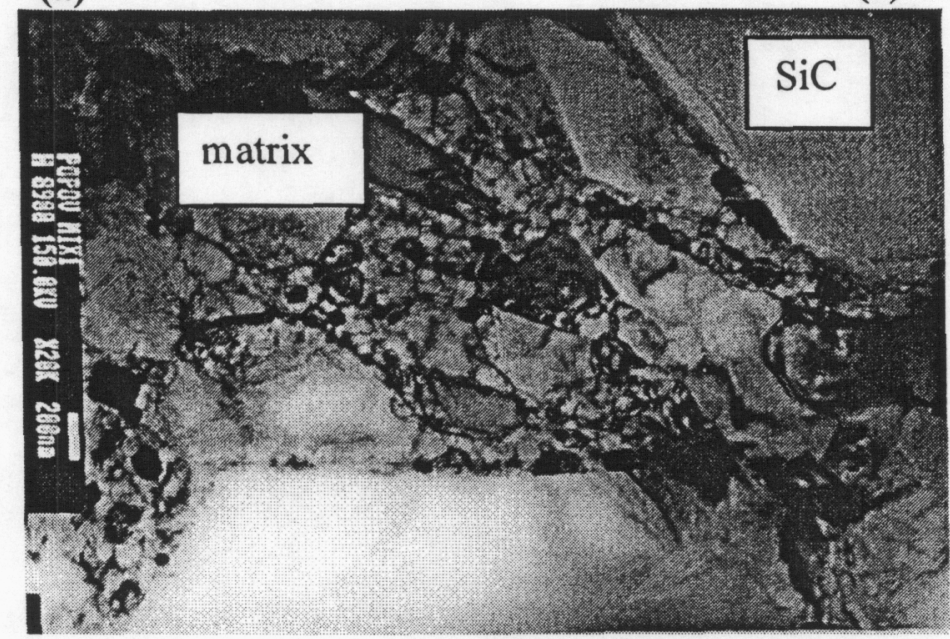

(c)

Figure 3. Third stage in the formation of matrix microstructure - consolidation of nanograins by the mechanism of collective recrystallization. (a)Aluminum matrix, (b) growth of the aluminum grains and (c) consolidated nano-scale aluminum grains between $\mathrm{SiC}$ particles. (TEM).

Microstructural examinations of the as-processed MMCs using TEM, SEM and optical microscopy showed dense compaction and a robust, well-defined interface between the Al nano-grains and the $\mathrm{SiC}$ particles. At each stage of $\mathrm{MMC}$ microstructure formation during compaction, the matrix material adheres well to the $\mathrm{SiC}$ particles. Even during the first stage of structure formation, the aluminum nano-powder is uniformly distributed and fills all regions between the particles. As shown in Fig. 4, good contact between the matrix and SiC particles was obtained even at sharp edges and extrusions. During further development of the structure, one can see dense contact between the $\mathrm{SiC}$ particles and the $\mathrm{Al}$ matrix throughout the entire volume of MMC. This observation is illustrated by Fig. 5, which shows a narrow (200-300 nm wide) region between particles. This region is completely filled with nano-scale grains that show good contact between themselves and the $\mathrm{SiC}$ particles. During transition to the third stage of microstructure development (grain growth by collective recrystallization), excellent contact is maintained between the matrix and the reinforcing particles. This point is illustrated by Figure 6 which shows a large inclined region at the interface between the aluminum matrix and a $\mathrm{SiC}$ particle. The interface is well defined and doesn't show any deleterious phases or reaction products (such as $\mathrm{Al}_{4} \mathrm{C}_{3}$ ), which would compromise the strength of the interface. 


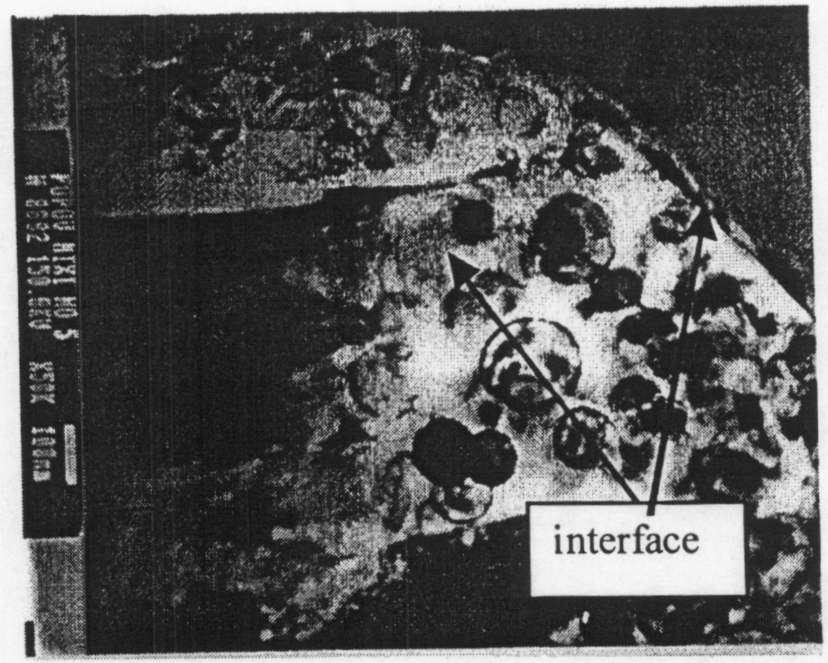

Figure 4. Dense distribution of nano-scale particles in cavities between $\mathrm{SiC}$ reinforcement. Micrograph shows dense contact between Al nano-particles and reinforcement. (TEM).

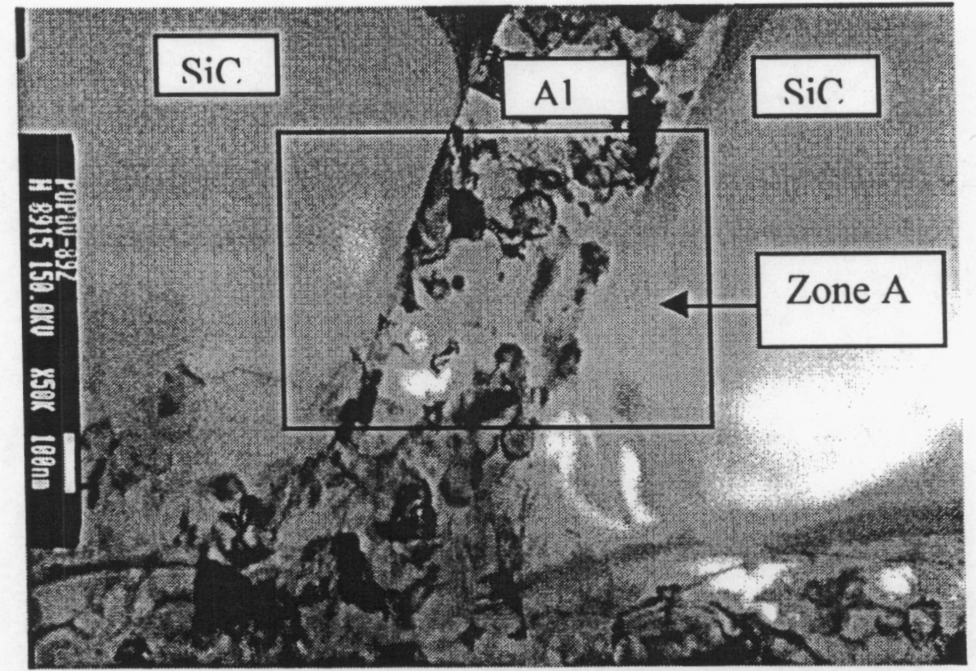

(a)

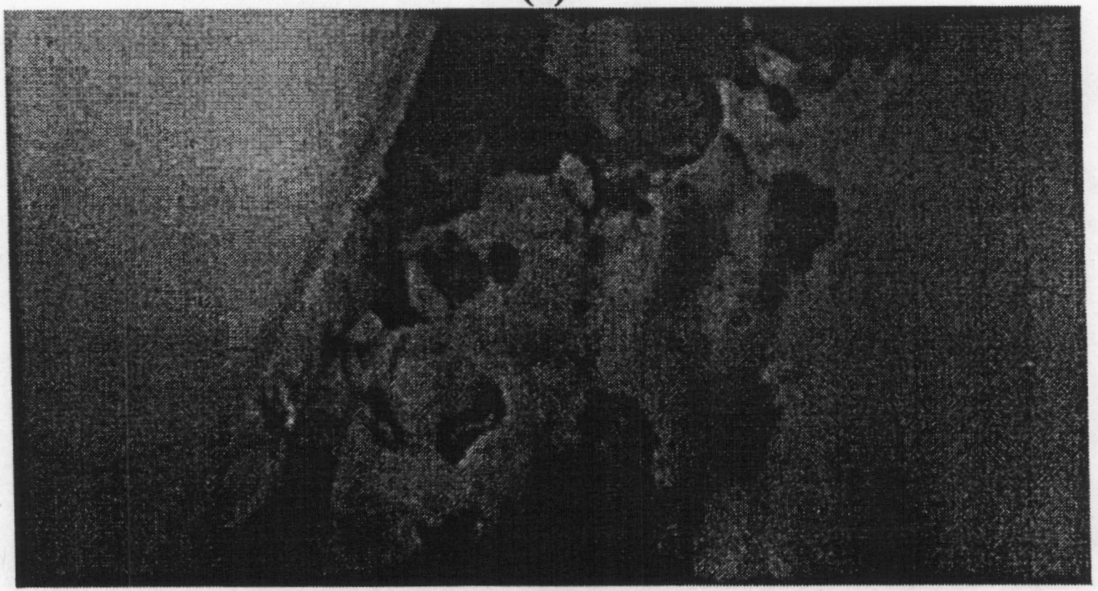

(b)

Figure 5. Micrograph showing a 200-300 nanometer-wide gap between reinforcing particles. The gap is completely filled by the aluminum nano-grains. (a) Dense contact between aluminum nano-grains and SiC particles during the second stage of microstructure development and (b) additional detail in Zone A from (b). (TEM). 


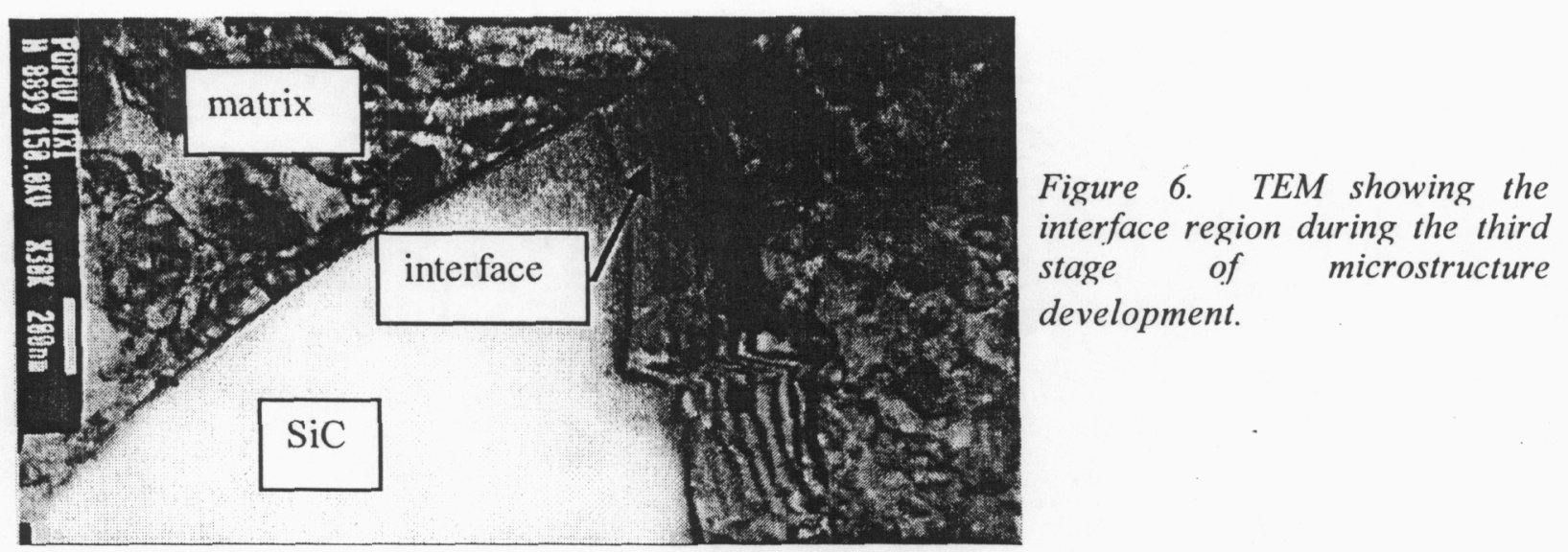

\section{Conclusions}

Dynamic loading using a magnetic impulse technique has been used to compact a MMC consisting of nano-scale $\mathrm{Al}$ powders and $\mathrm{SiC}$ reinforcement. The resulting product had a uniform distribution of the reinforcing phase and a dense matrix with a grain size of 100-200 nm. The matrix did not show any voids or incompletely compacted regions. The magnetic impulse technique produces a matrix with minimal grain growth during compaction. In addition, the process produced sharp, well-bonded interfaces between the nano-scale $\mathrm{Al}$ grains and the $\mathrm{SiC}$ reinforcement and did not lead to the formation of any interface phases such as $\mathrm{Al}_{4} \mathrm{C}_{3}$. Three distinct stages of microstructure development during dynamic compaction have been observed.

\section{References}

1. O.T. Midling and O. Grong, in Key Engineering Materials, Trans. Tech. Pub., 104-107, (1995), 329-354.

2. V. Kevorkijan, JOM, 11 (1999), 54-58.

3. Yu.A.Kotov, E.I. Azarkevich, I.B. Beketov, T.M. Demina, A.M. Murzakaev, O.M. Samatov, "Producing $\mathrm{Al}$ and $\mathrm{Al}_{2} \mathrm{O}_{3}$ Nanopowders by Electrical Explosion of Wire", Key Engineering Materials, Trans. Tech. Pub., 132-136, (1997), 173-176.

4. I.B. Beketov, Yu.A. Kotov, A.M. Murzakaev, O.M. Samatov, V.P. Volkov, R. Bohme, G. Schumacher, "Synthesis of $\mathrm{Al}_{2} \mathrm{O}_{3}, \mathrm{TiO}_{2}$ and $\mathrm{ZrO}_{2}$ Nanopowders by Electrical Explosion of Wires", in Proceedings of the International Symposium on Metastable, Mechanally Alloyed and Nanocrystalline Materials (ISMANAM-95), Canada, 1995, Materials Science Forum, 225-227 (1996), 913-916.

5. Yu. A. Kotov, E.I. Azarkevich, I.B. Beketov, A.M. Murzakaev, "Synthesis of Nanometersized Powders of Alumina Containing Magnesia". Ninth International Conference on Modern Materials \& Technology, Florence, Italy, (1998), 28.

6. V. Ivanov, S. Paranin, V. Khrustov, A. Medvedev, "Fabrication of Articles of Nanostructured Ceramics Based on $\mathrm{Al}_{2} \mathrm{O}_{3}$ and $\mathrm{ZrO}_{2}$ by Pulsed Magnetic Compaction and Sintering", Ninth International Conference on Modern Materials \& Technology, Florence, Italy, (1998), 54. 
7. V. Ivanov, S. Paranin, A. Nozdrin, "Principles of Pulsed Compaction of Ceramic Nanometer-sized Powders", in Key Engineering Materials, 132-136 (1997), 400-403.

8 V. Ivanov and V. Khrustov, "Preparation of Ceramics from Magnetic-pulsed-compacted Nanometer-sized $\mathrm{Al}_{2} \mathrm{O}_{3}$ Powder", Inorganic Materials, 34 (4), (1998), 401-404. 